\title{
Kaynak Uygulamaları Sonucunda Gemi Saclarında Meydana Gelen Distorsiyon ve Çarpılmaların Önlenmesine Yönelik Çalışmalar
}

\author{
Sitk1 Çırtlık ${ }^{*}$, Ömer Savaş² \\ 1* Sedef Gemi ARGE Merkezi, Tuzla, İstanbul, Türkiye, (ORCID: 0000-0002-9476-8752), SITKI.CIRTLIK@sedefshipyard.com \\ 2 Yıldız Teknik Üniversitesi, Gemi İnşaatı ve Denizcilik Fakültesi, İstanbul, Türkiye (ORCID: 0000-0001-7457-1457), o.savas@yildiz.edu.tr
}

(İlk Geliş Tarihi 17 Aralık 2021 ve Kabul Tarihi 25 Ocak 2022)

(DOI: 10.31590/ejosat.1059275)

ATIF/REFERENCE: Çırtlık, S. \& Savaş, Ö. (2022). Gemi ve Deniz Yapılarında Kaynak Uygulamaları Sonucunda İstenmeyen Şekil Değişimlerin ve Artık Gerilmelerin Önlenmesine Yönelik Çalışmalar. Avrupa Bilim ve Teknoloji Dergisi, (33), 251-257.

$\ddot{\mathbf{O} z}$

Bu Çalışmada, 10 mm kalınlıkta A grade AH 36 tip gemi imalatı sac parçaları toz altı kaynak methodu ile birleştirilmesi neticesinde ortaya çıkan çarpılma miktarları incelenmiş̧ir. Klas kuruluşları gemi saclarının kaynatılmasında, kaynatılan sacın kalınlığı ve kaynak yöntemimine bağlı olarak kaynak tatminkâr bir kaynak parametresi sunmaktadır. Ancak kaynak sonrasında ortaya çıkan çarpılma ve distorsiyon konusunda yeterli sonuç sunamamaktadır. Yapılan bu çalışmada DNV-GL klas kuruluşunun kaynak prosedürüne göre 10 mm kalınlıktaki sacların tozaltı kaynak yöntemi ile birleşitilmesi neticesinde ortaya çıkan çarpılma miktarları belirlenmiş ve optimum kaynak şartları ortaya konmuştur. Bununla birlikte çalışmada kaynak akımı, kaynaklı bağlantıların sabitlenmesi, ön tav durumu ve bölgesel değişim gibi kaynak parametrelerinin çarpılmaya etkileri incelenmiştir. Yapılan çalışmada sac kalınlığı ve kaynak prosedüründe yer alan parametrelere bağlı olarak malzemeye giren 1sı girdisinin malzemenin makro yapısında, sertliğinde ve distorsiyon miktarlarında bir takım değişikliğe sebep olduğu tespit edilmiştir. Ayrıca çalışma sonucunda, $10 \mathrm{~mm}$ kalınlıktaki AH 36 tipi gemi imalatı saclarının tozaltı kaynak yöntemi ile kaynatılmasında tatminkar bir bağlantı elde edilmesi için kaynak sırasında parçaların bağlanmadan, ön tav yapılarak ve 510 A kaynak akımı ile birleştirlmesi gerektiği tespit edilmiştir.

Anahtar Kelimeler: Kaynak prosedürü, gemi sacları, makro yapı incelemesi, distorsiyon miktarı.

\section{Studies on the Prevention Distortion and Warping Occuring in Ship Sheet as a result of Welding Applications}

\begin{abstract}
In this study, the amount of distortion resulting from the joining of $10 \mathrm{~mm}$ thick A grade AH 36 type ship building sheet metal parts with the submerged arc welding (SAW) method was investigated. Class societies offer a satisfactory welding parameter for the welding of ship plates, depending on the thickness of the welded plate and the welding method. However, it cannot provide sufficient results for warping and distortion after welding. In this study, according to the welding procedure of the DNV-GL class society, the amount of distortion resulting from the joining of $10 \mathrm{~mm}$ thick sheets with the submerged arc welding (SAW) method was determined and optimum welding conditions were revealed. In addition, the effects of welding parameters such as welding current, fixation of welded joints, preheating and regional variation on distortion were investigated in this study. In this study, it wasdetermined that the heat input entering the material depending on the parameters in the sheet thickness and welding procedure, caused some changes in the macro structure, hardness and amount of distortion of the material. In addition, as a result of study, it was determined that in order to obtain a satisfactory connection during welding of AH 36 type shipbuilding sheets of $10 \mathrm{~mm}$ thickness with the submerged arc welding method, the parts should be joined without connecting,preheating and with a welding current of 510 A during welding.
\end{abstract}

Keywords: Welding procedure, ship plate, macrostructure analysis, the amount of distortion.

* Sorumlu Yazar: SITKI.CIRTLIK@,sedefshipyard.com 


\section{Giriş}

Ülkemizde gemi sacı olarak farklı tiplerde çelikler kullanılmaktadır. Bunlardan Grade A çelik seri olarak üretilmektedir. Metal gemilerin yapımlarının kalitesi, güvenilirliği ve ekonomikliğini doğrudan etkilemektedir. Kaynaklı bağlantılar gemi inşasının bel kemiğini oluşturmaktadır (Asarkaya, 2002). Başlangıçta gemi inşaat alanında örtülü elektrot ark kaynak yönteminin yoğun bir şekilde kullanıldığ görülmektedir. Ancak gelişen teknoloji ile birlikte yarı-otomatik bir kaynak yöntemi olan gaz altı kaynak yöntemleri bu kaynak yönteminin yerini almıştır. (Ang, Lim, Lin 1999).

Anık ve Tülbentçi (2009) yüksek ergime ve kaynak hızına sahip kaynak yöntemlerinin başında toz altı kaynağının geldiğini belirtmişlerdir. Toz altı kaynak yönteminde, akım şiddetinin çok yüksek olması nedeniyle oldukça kaim parçaları rahatlıkla kaynak yapmak mümkündür. $\mathrm{Bu}$ durum ise daha az işçilik ve daha az malzeme sarfiyatına sebep olduğu belirtilmiştir ( Gülbahar, 1983). Ayrıca Lincoln (2000) yapmış olduğu çalışmada tozaltı kaynak yönteminde ergiyen bir toz koruma örtüsünün bulunduğunu, ark1 ve kaynak bölgesini korumak için kullanılmasıyla diğer kaynak yöntemlerinden farklılık gösterdiğini ifade etmiştir.

Malzeme içerisinde oluşan artı gerilme en kaba tanımıyla tüm dışsal yüklerin kaldırılması sonrasında kalan gerilme olarak tanımlanmaktadır ( Balık, 2008). Masubuchi (1980) yapmış olduğu çalışmada artık gerilmelerin yapının üzerindeki tüm dış yükler kaldırıldığında yapıda var olan gerilme olduğunu ifade etmiş olup ayrıca artık gerilmelerin üretim esnasında, kaynak, 1sıl işlem, çekme, delme, eğme, taşıma gibi nedenlerde oluşabileceğini ifade etmiştir.

Gemi inşa çeliklerinin iç yapısı ve tüm özelliklerinin tespiti için, uygun kaynak methodu ve dolgu malzemesinin seçimi, kaynak uygulaması sırasında yüksek isı sonucunda meydana gelen distorsiyonların sebepleri ve çözümlerinin, kaynak planlamaları ve kaynak parametre tercihlerinden kaynaklandığ belirtilmiştir (Asarkaya, 2006). Ayrıca Oğuz (1989) ve Şengel (2005) kaynağı yapılan malzemelerde meydana gelen deformasyonları etkileyen parametrelerin yapının rijitlik derecesi, malzemenin metalürjik özellikleri, 1sıl genleşme katsayısı, 1sıl iletkenlik katsayısı, kaynak hızı, kaynak metalinin ergime sıcaklığı, akma sınırı, elastiklik modülü olarak ifade etmiştir.

Sumper, Kent (2006) yapmış oldukları çalışmada gemi gibi dinamik yüklere maruz kalan yapı malzemlerin yorulma ve kırılma tokluğu gibi mekanik özelliklerinin bilinmesinin ve iyi olmasının önemli olduğunu rapor etmişlerdir.

$\mathrm{Bu}$ çalışmanın amacı, değişen birtakım parametreler birlikte toz altı kaynak yöntemleriyle birleştirilen AH36 saclar üzerinde meydana gelen çarpılma, makroyapı ve sertlik değişimleri incelemektedir. Ayrıca gemi saclarının kaynağındaen az çarpılma

meydana getiren kaynak parametreleri ve seviyeleri tespit edilecektir.

\section{Materyal ve Metot}

\subsection{Deneylerde Kullanılan Malzemeler ve Kaynak Parametreleri}

Yapılan çalışmda AH 36 gemi sacının alın alına tozaltı kaynağı sonucunda ortaya çıkan distorsiyonların belirlenmesine yöneliktir. Kaynak parametrleri olarak, kaynak akımı, ön tav durumu, parçalarının bağlama durumu ve bölgesel değişim şeklinde 4 farklı kaynak parametresi seçilmiştir. DNV-GL klas kuruluşunun kaynak prosedürü kullanılmıştır.

Parametre ve seviyeleri olarak Tablo 1'de görüleceği üzere kaynak akımı parametresi için 475, 510 ve 540 A, ön tav parametresi için ön tav uygulanmış ve ön tav uygulanmamış, sabitleme durumu parametresi için ise sabitlenmiş ve sabitlenmemiş seklinde parametre saviyeleri belirlenmiştir. Kaynak yönünde çarpılma miktarını belirlemek için kaynatılan bölgeden eşit aralaklarda üç bölgeden çarpılma ölçümü alınmıştır. Kaynak voltaj1 34 V'da sabit tutulmuştır. Kaynatılacak parçlar Şekil 1'de görüldüğü gibi $450 \mathrm{~mm}$ boyunda ve $150 \mathrm{~mm}$ boyunda kesilmiş ve kaynatılmadan önce gerekli kalınlık ölçümü Olympus 38 DL sertlik ölçüm cihazı ve dijital kumpas ile Şekil 1' deki gibi kontrol edilmiştir.

Tablo 1. Kaynak parametrleri ve onların seviyeleri (Table 1. Welding Parameters and Their Levels)

\begin{tabular}{|l|c|l|c|}
\hline & \multicolumn{3}{|c|}{ Kaynak Parametreleri ve Seviyeleri } \\
\hline Parametreler & 1. Seviye & 2. Seviye & 3. Seviye \\
\hline Bağlama Durumu & Sabitlendi & Sabitlenmedi & Sabitlenmedi \\
\hline Öntav Durumu & Ön tav uygulanmış & \multicolumn{2}{|c|}{ Ön tav uygulanmamış } \\
\hline Akım (A) & 475 & 510 & 540 \\
\hline Voltaj (V) & 34 & 34 & 34 \\
\hline Bölge & 1. bölge & 2. bölge & 3. bölge \\
\hline
\end{tabular}

Sabitlenerek kaynatılan saçlar ön ve arkasından punta ile sabitlenmiştir. Ön tav uygulanarak yapılılan kaynaklarda kaynak öncesinde parçalar yaklaşık $84^{\circ} \mathrm{C}$ 'ye tavlanmıştır. Şekil 2'de ön tav sonrası kaynak parçaları üzerinden ölçülen ön tav sıcaklığ görülmektedir.

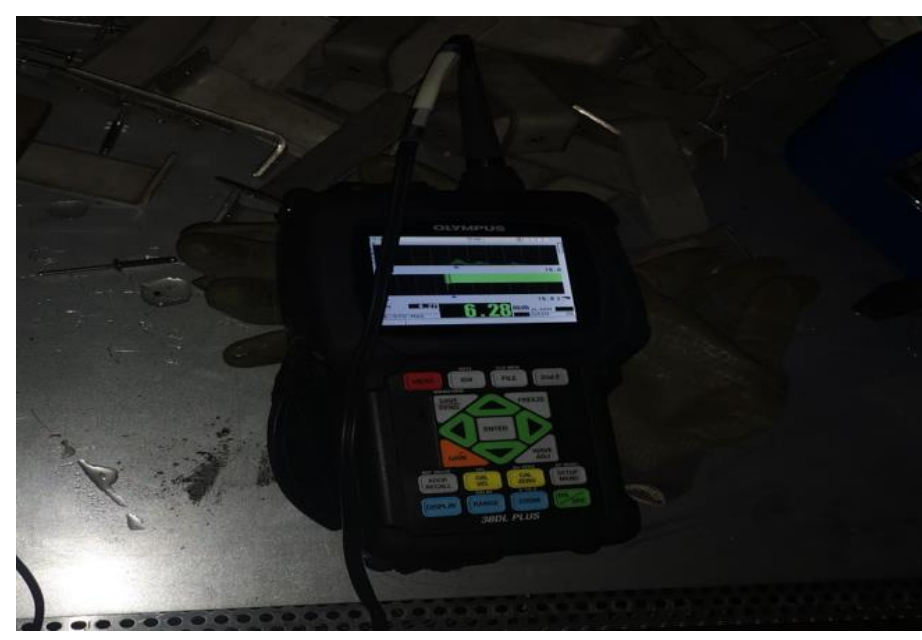

Şekil 1. Olympus Sertlik Ölçüm Cihazı (Figure 1. Olympus Hardness Measurement Experiment) 


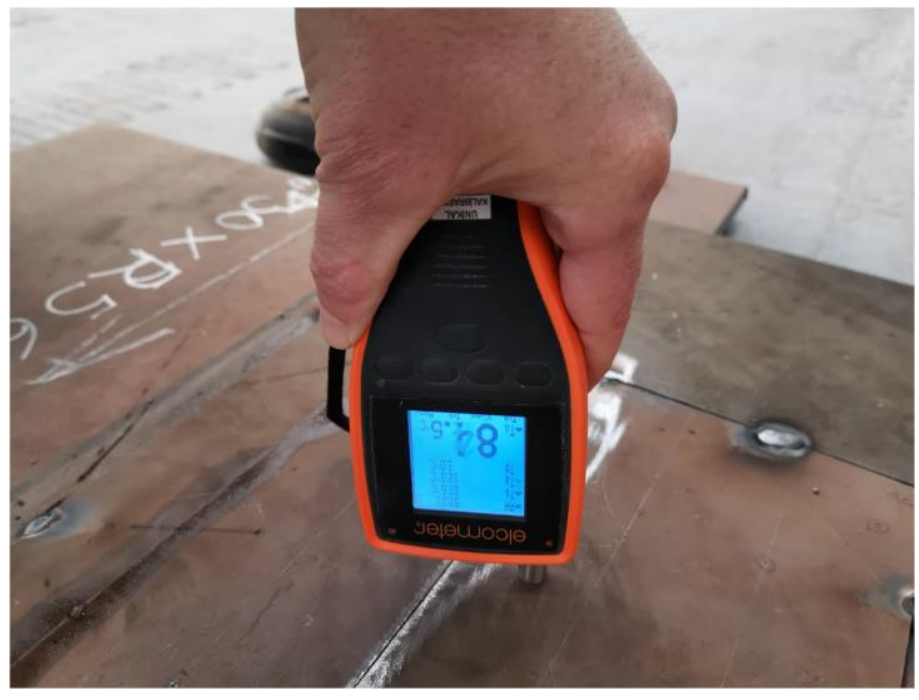

Şekil 2. Ön Tav Sonrası Numune Saclardaki Sıcaklık Değeri (Figure 2. Temperature Value in Samples Sheets After Preheat)

\subsection{Distorsiyon Miktarlarının Belirlenmesi}

Distorsiyon miktarlarını belirlemek için kaynatılacak parçalar üzerinde Şekil 3'de görüldüğü gibi kaynak yönünde $20 \mathrm{~mm}$ aralıklarla üç bölge belirlenmiş ve yatayda karşılıklı olarak 30 mm'lik mesafede işaretlenmiştir. Bu mesafeler kaynak öncesi ve kaynak sonrası ölçülerek kaynaklı parçanın ne kadar çarpıldığı cm cinsinden belirlenmiştir. Kaynak sonrasında belirlenen mesafeler arasında ki fark ne kadar fazla ise distorsiyon miktarınında o kadar fazla olacağı düşünülerek kaynak sonrası oluşan distorsiyon miktarı bu şekilde matematiksel olarak ifade edilebilmiştir.

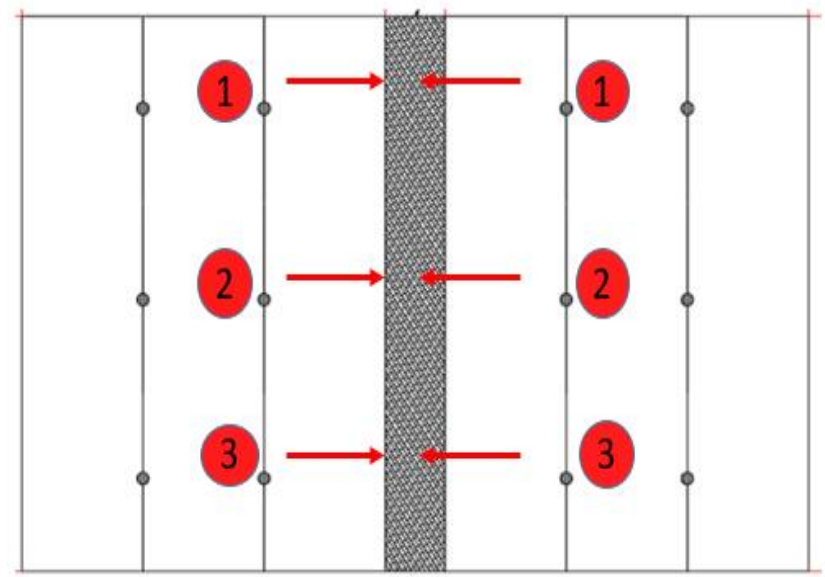

Şekil 3. Numunelerin Kaynak Sonrası Tek Yönlü Çekme Davranışları (Figure 3. Unidirectional Tensile Behaviours of Samples After Welding)

\subsection{Makroyapı ve Sertlik ölçümleri}

DNV-GL kaynak prosedürü kullanılarak hazırlanan kaynak numuneleri Çizelge 1'de yer alan kaynak akım ve voltaj değerleri ile kaynatılmıştır. Kaynaklar $8.8{ }^{\circ} \mathrm{C}$ 'de \%57,50 nemlilik düzeyinde aynı çevresel şartlarda Sedef tersanesi yeni imalat atölyesinde yapılmıştır. Kullanılan parametreler için 1sı girdisi aşağıda verilen denklem kullanılarak hesaplanmıştır (Shome, 2007).

$$
H=\eta \frac{I x E}{V \times 1000}
$$

Eşitlikte $\mathrm{H}$ 1S1 girdisi( $\mathrm{KJ} / \mathrm{mm})$, E: arkdaki voltaj1 (V), v ise kaynak hızını (mm/s) ve son olarak I: kaynakdaki akımı (A) ifade etmektedir. $\mathrm{y}$ ise kaynak verimi olup boyutsuz bir sayıdır. Shome'un (n.d.) çalışmasında olduğu gibi tozaltı kaynağı için ark verimi 0.95 olarak kabul edilmiştir.

Kaynak sonrasında kaynatılmış parçalardan $70 \times 40 \mathrm{~mm}$ ebatlarında numuneler kesilmiş olup gerek makro yapı incelemesi gerekse sertlik ölçüm deneyi için uygun hale getirilmiştir. Numuneler 80 ile 1200 grid zımpara kademesi arasında ki SiC su zımaparası zımparalanmış ve ardından parlatılmıştır. Sonra kaynak bölgesinin belirgin hale gelmesi için nital asidik çözeltisi içine daldırılarak dağlama işlemi yapılmıştır. Dağlama işlemi tamamlandıktan sonra $4 \mathrm{XB}$ metalürjik mikroskop ile gerekli incelemeler yapılmıştır.

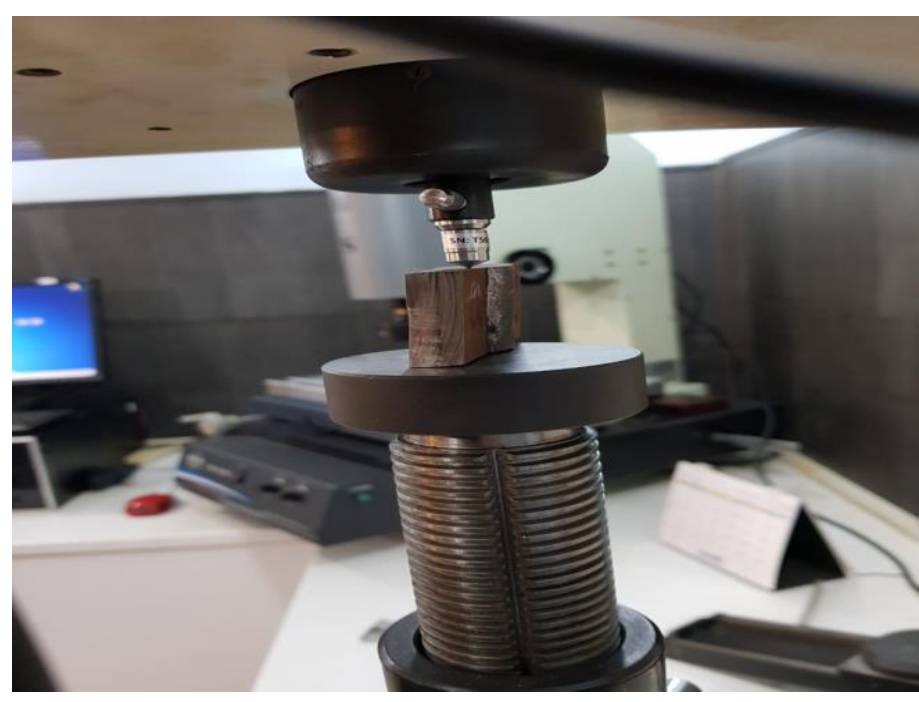

Şekil 4. Vickers Sertlik Ölçüm Deneyi (Figure 4. Vickers Hardness Measurement Experiment)

Sertlik ölçümümleri için Vickers sertlik prosedürü uygulanmıştır. Bu deney yönteminde sivri uc olarak olarak tepe açısı $136^{\circ}$ elmas kare piramit kullanılmış olup 57 noktadan sertlik ölçüöü alınmıştır. Deneylerde Şekil 9'da görülen, QVV mühendislik firmasında yapılan sertlik ölçümlerinde HADIA HD-HV-10 marka sertlik ölçüm cihazı kullanılmıştır. 


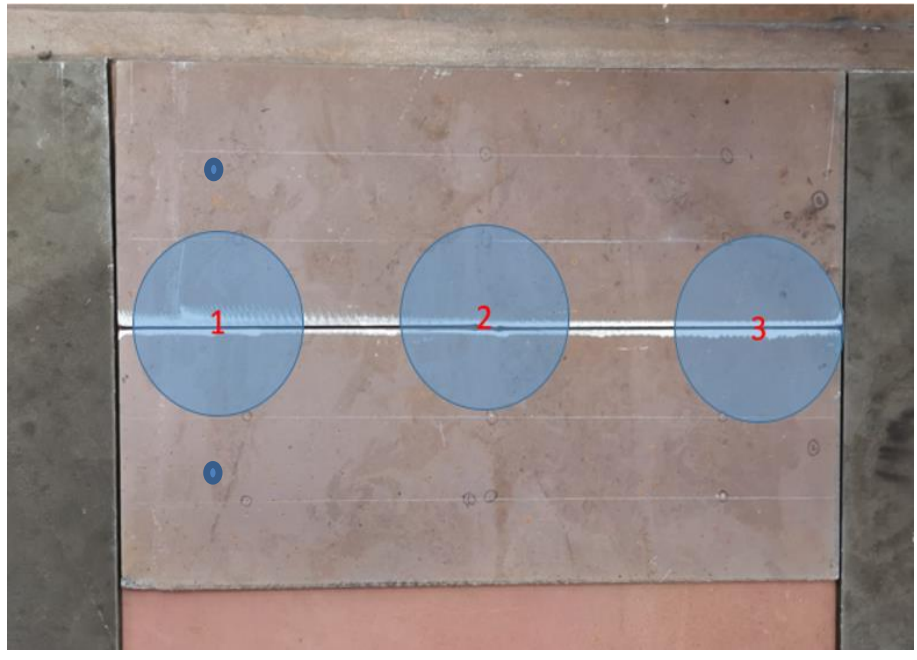

Sekil 5. 450 $\times 150 \mathrm{~mm}$ Toz Altı Kaynak Numenelerinin

Hazırlanışl ve Kaynak Sirası (Figure 5. Preparation of $450 \times 150$ mm Submerged Welding Samples and Welding Sequence)

\section{Araştırma Sonuçları ve Tartışma}

Tablo 2'de kaynak sonrasında üç bölgeden ölçülen çarpılma miktarları verilmiştir. Tabloda en büyük çarpılmanın sabitlenmeden, ön tav uygulanmadan 510 A kaynak akımında kaynatılan parçalarda $0,550 \mathrm{~cm}$ olduğu görülmektedir. En küçük çarpılma değeri ise sabitlenmiş, ön tav uygulanmamış ve 475 A'de kaynatılan parçalarda ortalama $0,083 \mathrm{~cm}$ olarak ölcülmüştür. Tabloda çarpılma miktarı ile 1 sı girdisi arasında paralellik gösterdiği görülmektedir. Tablo 2'de kullanılan deney numaraları kapsamında bağlama durumları, ön tav durumu, Akım değerleri, voltaj, ısı girdisi ve yapılan kaynak sonrası çarpılma miktarları belirtilmiştir.
Tablo 2. Deney Numaralarl ve Parametreler (Table 2. Experiment Numbers and Parameters)

\begin{tabular}{|c|c|c|c|c|c|c|c|}
\hline Deny No & Bağlama Drovo & Oon Tav Durumv & $\operatorname{Askm}(A)$ & $\begin{array}{l}\text { Kaynal: } \\
\text { Böleses }\end{array}$ & Vottaj (V) & Is Girdisi (thil & Cropilma Mittran $(\mathrm{cm})$ \\
\hline & 1. Sabitlenmis & Ön Tav uygularmis & 475 & 5 1. bolge & 34 & 0,426 & 0,07 \\
\hline & 2 Sabitlermis & Ön Tav uygularmis & 510 & o 1. bolge & 34 & 0,458 & 0,08 \\
\hline & 3 Sabitlenmis & ön Tav uygularmis & 540 & 1. bolge & 34 & 0,485 & 0,1 \\
\hline & 4 Sabitlermemis & $\partial_{n}$ Tsv uygularmis & 475 & 5 1. bolge & 34 & 0,426 & 0,27 \\
\hline & 5 Sabitlermemis & ön Tav uygularmis & 510 & of 1. bolge & 34 & 0,458 & 0,29 \\
\hline & 6 Sabitlermemis & $\partial_{n}$ Tav uygularmis & 540 & ol. bolge & 34 & 0,485 & 0,32 \\
\hline & Sabitlermemis & ón Tav uygularmam & 475 & 5 1. bolge & 34 & 0,426 & 0,26 \\
\hline & 8 Sabitlermemis & ön Tav uygularmant & 510 & of 1. bolge & 34 & 0,458 & 0,28 \\
\hline & of Sabitlermemis & $\partial_{\mathrm{n}}$ Tav uygularmam & 540 & l. bolge & 34 & 0,485 & 0,32 \\
\hline & of Sabitlermis & $\dot{o}_{\mathrm{n}} \mathrm{T}$ av uygularmis & 475 & 5 2. bolge & 34 & 0,426 & 0,1 \\
\hline & 1 Sabitlermis & ôn Tav uygularmis & 510 & | 2. bolge & 34 & 0,458 & 0,1 \\
\hline & 2 Sabitlermis & Ön Tav uygularmis & 540 & o 2. bolge & 34 & 0,485 & 0,11 \\
\hline & 3 Sabitlermemis & Ón Tav uygularmis & 475 & 5 2. bolge & 34 & 0,426 & 0,3 \\
\hline & 4 Sabitlermemis & $\dot{o}_{\mathrm{n}} \mathrm{T}$ av uygularmis & 510 & o. 2. bolge & 34 & 0,458 & 0,32 \\
\hline & 5 Sabitlermemis & ön Tav uygularmis & 540 & 2. bolge & 34 & 0,485 & 0,34 \\
\hline & 6 Sabitlermemis & ön Tav uygularmant & 475 & $5.2 .600 \mathrm{ges}$ & 34 & 0,426 & 0,3 \\
\hline & Sabitlermemis & ön Trv uygularmam: & 510 & o. 2. bolge & 34 & 0,458 & 0,31 \\
\hline & 8 Sabitlermemis & Ón Tav uygularmam & 540 & ol. bolge & 34 & 0,485 & 0,34 \\
\hline & o) Sabittlermis & ön Tav uygularmis & 475 & 5. 3olge & 34 & 0,426 & 0,08 \\
\hline & of Sabitlermiş & ön Tav uygularmis & 510 & o 3. bolge & 34 & 0,458 & 0,00 \\
\hline & Sabitlermis & $\partial_{n}$ Trv uygularmis & 540 & o. 3. bolge & 34 & 0,485 & 0,11 \\
\hline & 2 Sabitlermemis & ón Tav uygularmis & 475 & 5 3. bolge & 34 & 0,426 & 0,29 \\
\hline 23 & 3 Sabitlermemis & Ön Tav uygularmis & 510 & o 3. bolge & 34 & 0,458 & 0,3 \\
\hline & 4 Sabitlermemis & Ón Tav uygularmis & 540 & o 3. bolge & 34 & 0,485 & 0,33 \\
\hline 25 & 5. Sabitlermemis & On Trv uygularmam & 475 & 5. 3. bolge & 34 & 0,426 & 0,29 \\
\hline & 6 Sabitlermemis & ön Tav uygularmam & 510 & 0 3. bölge & 34 & 0,458 & 0,3 \\
\hline 27 & Ssabitlermemis & ön Tsv uygularmamt & 540 & 0 3. bölge & 34 & 0,485 & 0,33 \\
\hline
\end{tabular}

Şekil 6'de kaynatılan parçalarının 1, 2 ve 3 bölgelerinden alınan ortalama çarpılma miktarkarının grafiksek gösterimi verilmiştir. Grafikte 1. Bölgede çarpılma miktarı çok düşükken en yüksek çarpılma miktarı 2. Bölgede gözlenmiş ve 3. Bölgede düşmüştür. Çarpılma miktarının 2. Bölgede en yüksek değerine ulaşıp ardından düşmeye başlamasının nedeni kaynaklı parçaların ısınarak parçayı tavlamış olmasından kaynaklandığı düşünülmektedir. 


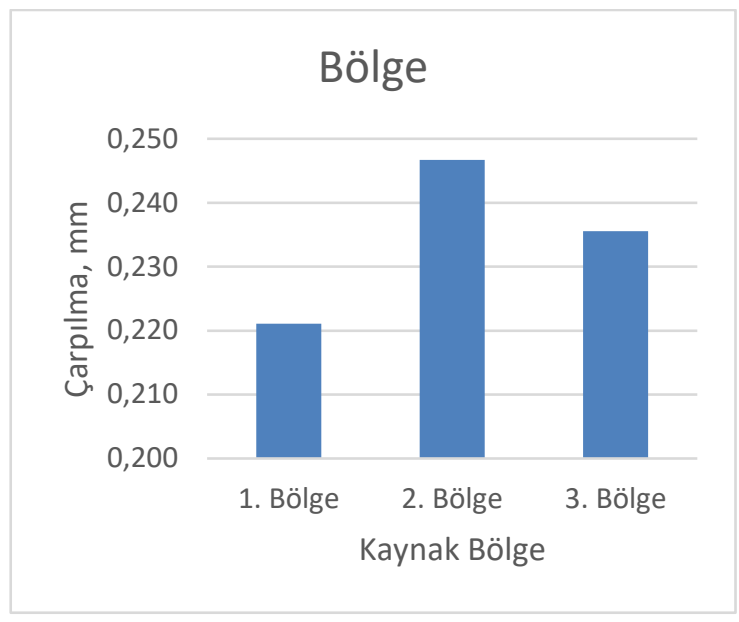

Şekil 6. Kaynak Bölgesinin Çarpılmaya Etkisi (Figure 6. Effect of Source Region on Distorstion)

Şekil 7'de kaynak akımı ile çarpılma miktarındaki değişim görülmektedir. Şekil 2'de artan kaynak akımı ile çarpılma miktarının da arttığı görülmektedir. Çarpılma miktarı 475 A'de kaynatılan numunelerde ortalama $0,218 \mathrm{~cm}$ iken 510 A'de ortalama $0,230 \mathrm{~mm}$ ve 540 A'de ortalama $0,256 \mathrm{~mm}$ seviyelerinde olduğu görülmektedir. Artan akım şiddeti ile çarpılmanın artmasının muhtemel nedeni artan akım şidddeti ile Tablo 1'de görüldüğü gibi 1S1 girdisinin artmasından kaynaklanmıştır. Frickle, Kahl (2005) yapmış olduğu çalışmalar bu çalışma elde edilen değerleri doğrulamaktadır

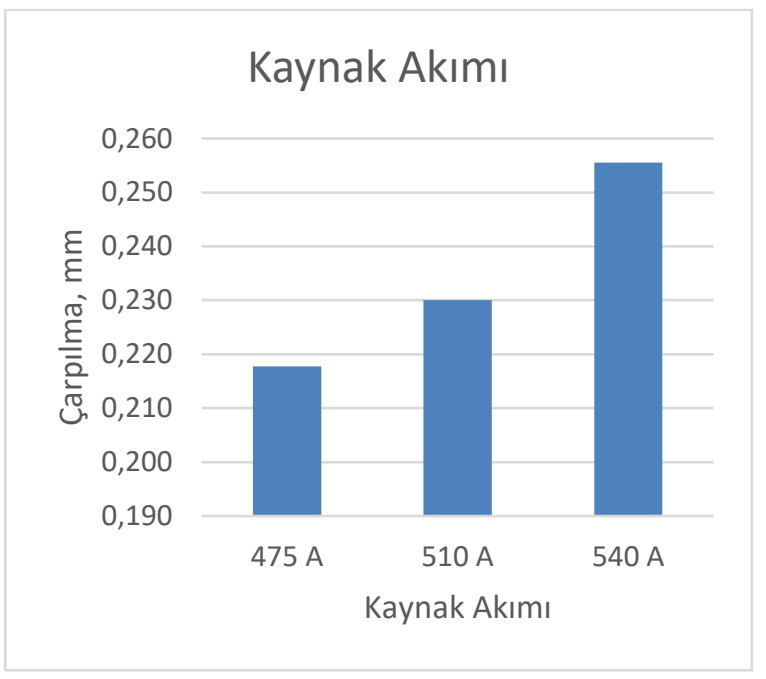

\section{Şekil 7. Kaynak Akımnın Çarpılmaya Etkisi (Figure 8. Effect of Welding Current on Distortion)}

Şekil 8'de Kaynaklı parçalara ön tav durumunun çarpılmaya etksininin grafiksel gösterimi verilmiştir. Grafikte ön tav uygulanan kaynaklı parçalarda çarpılma miktarı ortalama 0,287 $\mathrm{cm}$ iken tavlanmayan kaynaklı parçalarda $0,303 \mathrm{~cm}$ olduğu görülmektedir. Verilen bu sonuç kaynaklı parçalarının ön tav uygulanması durumunda çarpılma miktarını önemli oranda düşürdüğünü göstermekedir. Bu sonuç yapılan önceki çalışmlarla önemli oranda paralellik göstermektedir.

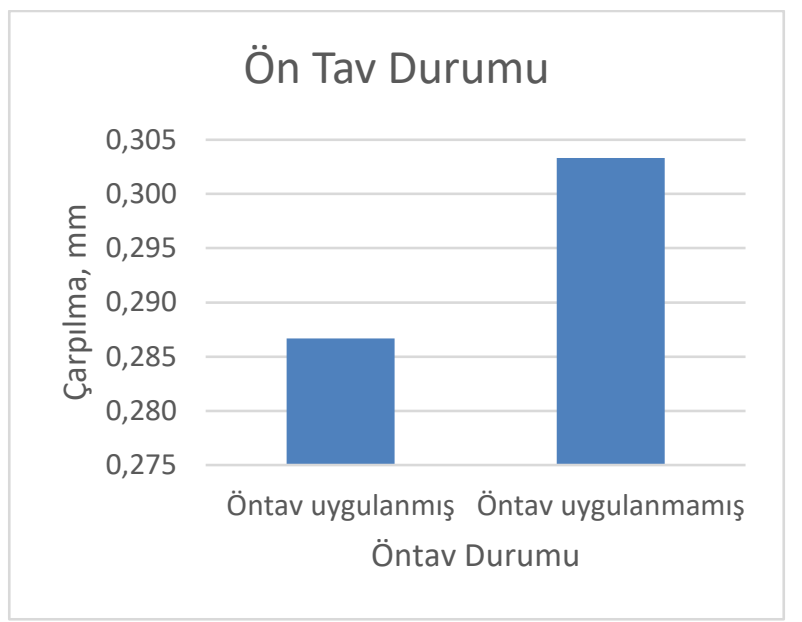

Şekil 8. Ön Tavın çarpılmaya Etkisi (Figure 8. Effect of Preheating on Distortion)

Şekil 9'de kaynaklı parçalarını puntalanarak sabitlenmesi durumununda çarpılmaya etsini göstermektedir. Grafikta kaynaklı parçalarının sabitlenmesi durumunda çarpılmanın daha az, sabitlenmemesi durumunda ise daha yüksek olduğu görülmektedir. Kaynaklı parçalar sabitlendiği durumde ortalama $0,093 \mathrm{~cm}$ çarpılma gözlemlenirken, sabitlenmemiş durumunda ise ortalama $0,305 \mathrm{~cm}$ çarpılma tespit edilmiştir. Bu sonuç aslında parçalarının sabitlenmesi durumunda parça içerisinde ne kadar distorsiyona neden olduğunu açıkça göstermektedir. Yani parça sabitlenmediğinde $0,305 \mathrm{~cm}$ çarpılacakken sabitlendiği için 0,093 $\mathrm{cm}$ çarpılmıştır. Geriye kalan çarpılma $(0,305-0,093 \mathrm{~cm})$ parça içerisinde artı gerilmeye sebep olmuştur.

$\mathrm{Bu}$ nedenle kaynatılacak parçalararın sabitlenmeden, en az çarpılma oluşturacak şekilde kaynaklanması gerekir.

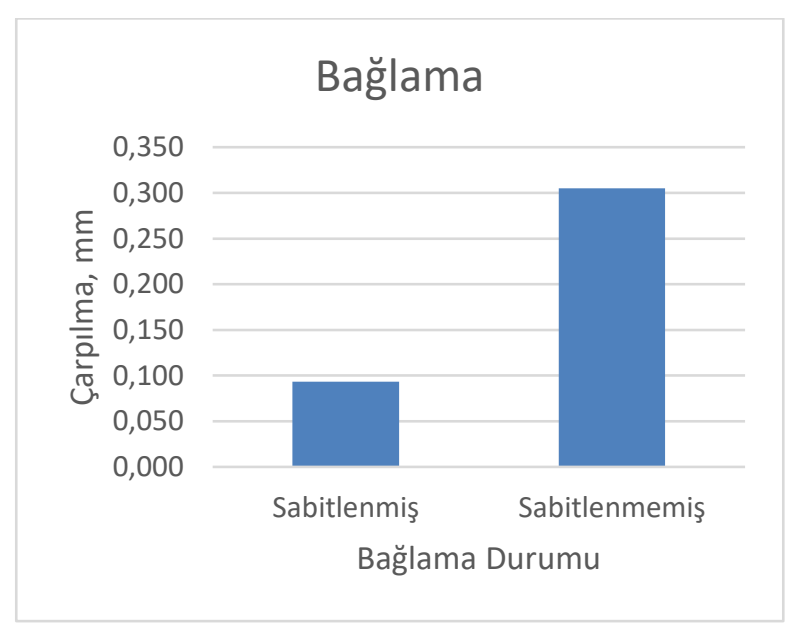

Şekil 9. Kaynak Parçalarının Sabitlenmesinin Çarpılmaya Etkisi (Figure 9. Effect of Fixing Weld Pieces on Distortion)

QVV mühendislik atölyesinde nemin \%55 sıcaklığın $21^{\circ} \mathrm{C}$ olduğu ortamda yapılan sertlik ölçümü deneyinde HAIDA marka vickers sertlik ölçüm cihazı kullanılmıştır. Yapılan bu ölçüm TSEN ISO9015-1 standartlarında olup her bir deneyde 57 noktadan ölçüm alınmıştır. 


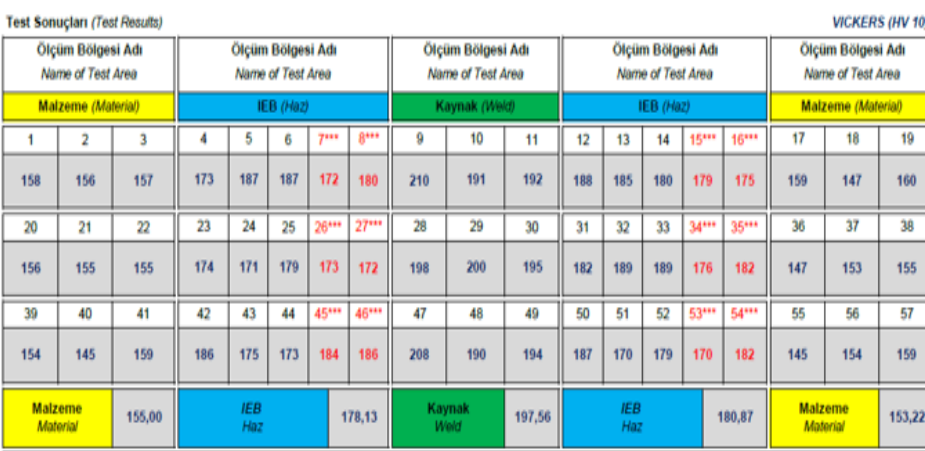

Şekil 10. Sertlik Ölçüm Sonuçları (Figure 10. Hardness Measurement Results)

Deney numuneleri için yapılan sertlik ölçümü sonucunda ana malzemelerde sertlik 150-153 HV arasında değişmekte olup 1S1 tesiri altında kalan bölgede sertliğin daha da arttığı, sertliğin 178 ile $181 \mathrm{HV}$ arasında değişim gösterdiği tespit edilmiştir. Sertliğin en yüksek olduğu kaynak bölgesinde yapılan sertlik ölçümünde ise 197 ile $203 \mathrm{HV}$ arasında sertlik ölçüm elde edilmiştir. Kökemli'nin (2005) daha önce yapmış olduğu bir çalışmada da bu çalışmada ya benzer sonuçlar elde edildiği sahip olunan sertlik değerlerinin birbirine yakın olduğu tespit edilmiştir. Bahsedilen çalışmada, tozaltı kaynağı ile kaynağı yapılan düşük karbonlu bir malzemenin 1s1 tesiri altında kalan bölgede ince taneli bölgede sertlik değerleri $190 \mathrm{HV}$ iken iri taneli bölgelerin sertlik değerleri $140 \mathrm{HV}$ civarında olduğu ifade edilmiştir. Yılmaz (2018) yapmış olduğu çalışmada değişen kaynak türleri ve parametre değerleri için benzer sonuçlar elde edilmiştir.

Elde edilen tüm bu sonuçlar Türk loydu ve diğer klas kuruluşlarınca belirlenen limitler dahilinde olduğu tespit edilmiştir. Türk loydu'nun Kaynak kuralları kısım-3 de yer alan kurala göre yüksek mukavemetli tekne yapım çelikleri için tercih edilen kaynak ve kaynak yardımcı malzemelerinin kaynak metaline ait serliği $150 \mathrm{HV}$ den az olmaması gerektiği belirtilmiştir.

Ayrıca Eroğlu ve Aslan (2001) yapmış olduğu çalışmada, kaynağı yapılan malzemelerde enerji girişinin artışını, sertlikte düşüşe neden olmasına ve kaynak sonrasında sünek fazların oluşmasına sebep olduğunu belirtmişlerdir.

Kaynaklı bölgelerinin makro incelemelerinde 510 ve $540 \mathrm{~A}$ kaynak akımında yapılan kaynaklarda nufuziyetin yeterli olduğu görülmüştür. Yapılan makro yapı incelemelerinde artan kaynak akımı ile nufuziyetin arttmasına karşın 1sı tesiri altında kalan bölgenin genişleyip arttığı görülmüştir. Buna karşın 475 A'de kaynatılan parçalarda nüfuziyet yetersizliği gözlemlenmiştir. Şekil 12'de 475 A kaynak akımı ile kaynatılan parçadan alınan makro yapı görüntüsü verilmiştir. Şekilde kaynaklı parçada nufuziyet eksikliği açıkça görülmektedir. Şekil 13'de 540 A kaynak akımı ile kaynatılan numuneye ait makro yapı görüntüsü verilmiştir. Resimde kaynak konsiriksiyonunda nüfuziyetin yeterli olduğu, buna karşı 1S1 tesiri altında kalan bölgenin genişlediği 1s1 girdisinin arttığı görülmektedir.

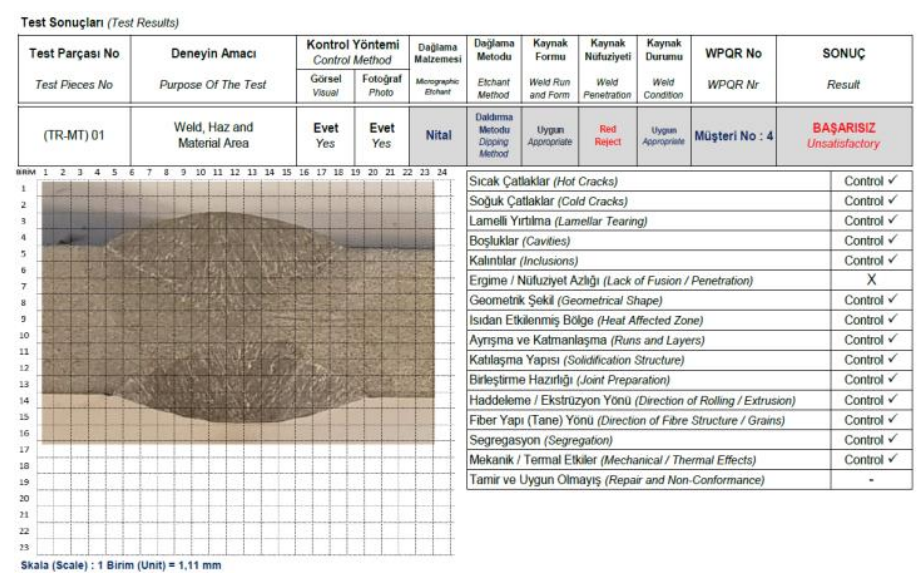

Şekil 11. $10 \mathrm{~mm}$ Toz Altı Kaynă̆ Makro Yapı İncelemesi Nüfuziyet Eksikliği (Figure 11. $10 \mathrm{~mm}$ Submerged Arc Welding Macro Structure Investigation Lack of Penetration)

$10 \mathrm{~mm}$ toz altı kaynağı ile yapılan 475 amper ve 34 voltajla kaynağı yapılan numaralı numune haricinde diğer numuneler de yapılan makro yapı incelemesinde sıcak-soğuk çatlaklar, ergime durumu, katılaşma yapısı vb. incelemelerde herhangi bir uygunsuzluğa rastlanmamıştır.

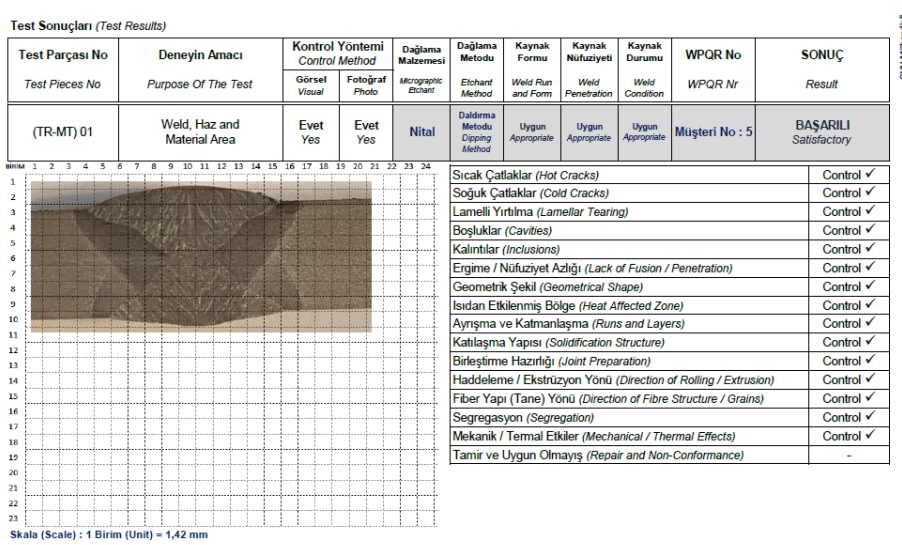

Şekil 12. 10 mm Toz Altı Kaynă̆ Makro Yapı İncelemesi (Figure 12. $10 \mathrm{~mm}$ Submerged Arc Welding Macro Structure Investigation)

Yukarıda elde edilen sonuçlar, kaynaklı balantılarda çarpılmanın azaltılması için ön tav uygulanması ve kaynak akımının düşük tutulması gerkmektedir. Ancak artan kaynak akımıla birlikte 1sı girdisini artırarak çarpılma miktarının arttığı görülmektedir. Çarpılmanın düşürülmesi için akım şiddetin düşük tutulması gerekmektedir. Ancak Şekil 2'de verilen makro yapı incelemeleri sonucunda akım şiddetinin düşürülmesi nufuziyeti düşmektedir. Buda sağlıklı bir bağlantı yapılamamasına neden olmaktadır.

Yapılan bu çalışmada, $10 \mathrm{~mm}$ kalınlıktaki gemi saclarının tozaltı kaynak yöntemi ile birleştirilmesinde, en az distorsiyonla yeterli nufuziyet elde etmek için ön tav uygulanması ve 510 A'de kaynatılması gereklidir. 


\section{Sonuç}

$\mathrm{Bu}$ çalışmada $\mathrm{AH} 3610 \mathrm{~mm}$ saclar toz altı yöntemleri ile birleştirilmiştir. Yapılan bu çalışmalar sonucunda elde edilen sonuçlar maddeler halinde sunuluştur;

1. Klas kuruluşları kaynak parametrelerinden faydalınarak hazırlanan bu çalışmada 3 farklı amper (475, 510 ve 540 A) değeri ele alınmıştır. Akım değerinin düşürüldüğü dolayısıyla ısı girdisinin düştüğü durumlarda distorsiyon miktarının azaldığı fakat 1sı girdisi azaldığından dolayı kalın saclarda nüfuziyet eksikliği olabileceği tespit edilmiştir. Akım değerinin maksimum seçildiği durumlarda ise nüfuziyet probleminin yaşanmadığı fakat çarpılma miktarında gözle görülür artış olduğu belirlenmiştir.

2. Kaynak öncesinde kaynak parçaları punta ile sabitlendiğinde çarpılma miktarının azaldığı fakat numuneler sabitlendiğinden dolayı distorsiyonun numunelerin kaynak bölgesinde biriktiği gözlemlenmiştir.

3. Ön tav uygulaması yapıldığında çarpılma miktarının azaldığı tespit edilmiştir.

4. Sertlik değeri incelendiğinde, tüm kaynak parametreleri için ana malzeme, 1sı tesiri altında kalan bölge ve kaynak bölgesinde çatlak riskine sebep olabilecek sertlik değerinin limitin dışına çıkmadığı tespit edilmiştir.

5. $10 \mathrm{~mm}$ kalınlıktaki gemi saçlarının tozaltı kayanak yöntemi ile birleştirilmesinde, en az distorsiyonla yeterli bir yeterli nufuziyet elde etmek için öntav uygulanması gerektiği ve 510 A'de kaynatılması gerektiği rapor edilmiştir.

\section{Teşekkür}

Sedef Tersanesi ARGE 18-P2 kodlu proje kapsamında hazırlanan bu çalışmaya katkılarından dolayı başta Turan ÇUBUUĞUZUN, İbrahim DOMAÇ, Canberk ERDOĞAN ve AR-GE birimi yöntecisi Hilal Kılınç olmak üzere tüm Sedef Tersanesi çalışanlarına ve QVV mühendislik firmasına teşekkür ederim.

\section{Kaynakça}

Anık, S. \& Tülbentçi, K. (2009), Tozaltı Kaynak Tekniği. Böhler Kaynak Çubukları, ElektrodlarıSan. Ve Tic. A.Ş. İstanbul.

Asarkaya, M.(2006), Gemi İnşasında Kullanılan Kaynak Yöntemlerinin Mekanik Özelliklere Etkisi, Y. Lisans Tezi. Fen Bilimleri Enstitüsü.

Asarkaya, M. (2004), Tersanelerde Uygulanan ve Uygulanabilecek Kaynak Yöntemleri, Gemi Mühendisliği ve Sanayimiz Sempozyumu, s.252-267.

Balık, B. E., , (2008), Gemi inşaatında kaynak sırası yöntem iliş̧isi ve kaynak muayene planlarının incelenmesi, Fen Bilimleri Enstitüsü, Yıldız Teknik Üniversitesi.
Eroğlu, M., Aslan, S., (2001), Düşük Karbonlu Bir Çelikte Molibdenin ITAB'ın Mikroyapısı ve Mekanik Özelliklere Etkis, 127-135, Kaynak Teknolojisi III Ulusal Kongresi, 1920 Ekim, İstanbul.

Gülbahar, B. (1983), Oerlikon Tozaltı Kaynak Yöntemi Seminer Notları. İstanbul.

IACS, (2006), Shipbuilding and Repair Quality Standards, International Association of Classification Societies.

J.D.G. Sumpter, J.S. Kent, (2006), Fracture toughness of grade D ship steel", Engineering Fracture Mechanics, 73, pp.13961413.

Kökemli, K., Kaçar R., (2005), Kontrollü Atmosferin Gaz Alt1 Ark Kaynak Bağlantılarının Isı Tesiri Altındaki Bölgesi Özelliklerine Etkisi, G.Ü. Fen Bilimleri Dergisi, 18, s.671680.

Lincoln, J. (2000), The procedure Handbook of Arc Welding, (12th Edition), The Lincoln Elektric Company.

M.H. Ang, W. Lin, S.Y. Lim, (1999), A Walk-Through Programmed Robot for Welding in Shipyards" Industrial Robot, 26, 5, pp. 377-388.

M. Shome, (2007), Effect of Heat-input on Austenite Grain Size in The Heat-Affected Zone of HSLA-100 Steel", Materials Science and Engineering A, 445-446, pp. 454-460.

Oğuz B., (1989), Malzeme Bilgisine Giriş, Kaynakçının Rehber Kitaplar1,1, İstanbul.

Şengel, M.A, (2005) Gemi Üretiminde Kaynak Nedeniyle Oluşan Deformasyonlar ve Artık Gerilmeler, Y. Lisans Tezi, Fen Bilimleri Enstitüsü, İstanbul Teknik Üniversitesi.

Türk Loydu, (2013), Gemi İnşaatı ve Onarımı Kalite Standartları, Yeni İnşa Edilen Gemiler İçin İnşaat ve Düzeltme Kalite Standartları, Türk Loydu Yayınları, İstanbul.

Yılmaz, A.F., (2018), Gemi İnşaatındaki Kaynaklı Bağlantıların Yapısal ve Mekanik Özelliklerin Optimizasyonu, Y.Lisans Tezi, Fen Bilimleri Enstitüsü.

W. Fricke, A. Kahl, (2005), Comparison of Different Structural Stress Approaches for Fatigue Assessment of Welded Ship Structures, Marine Structures 18, pp. 473-488 